\begin{tabular}{l} 
RCCS \\
\hline Annual Review
\end{tabular}

\section{RCCS Annual Review}

A selection from the Portuguese journal Revista Crítica de Ciências Sociais

$4 \mid 2012$

Issue no. 4

\title{
Models of Social Vulnerability to Disasters
}

David Alexander

URL: http://journals.openedition.org/rccsar/412

DOI: $10.4000 /$ rccsar.412

ISSN: 1647-3175

Publisher

Centro de Estudos Sociais da Universidade de Coimbra

\section{Electronic reference}

David Alexander, « Models of Social Vulnerability to Disasters », RCCS Annual Review [Online], 4 | 2012,

Online since 01 October 2012, connection on 30 April 2019. URL : http://journals.openedition.org/

rccsar/412 ; DOI : 10.4000/rccsar.412 


\section{David Alexander}

Global Risk Forum, Davos, Switzerland

\section{Models of Social Vulnerability to Disasters*}

This paper discusses the bases of theory in the evaluation of social vulnerability to disasters. Vulnerability is shown to be the vital component of risk and the principal element of disaster impacts. Perception is a key process in decision making in disasters. It is affected by culture and symbolism, which are analysed in the context of disaster risk. A model of cultural metamorphosis is used to explain changes and discrepancies in attitudes to disaster and recovery processes. The response to the L'Aquila (central Italy) earthquake of 6 April 2009 is discussed as an illustration of processes of cultural metamorphosis and symbolic interpretation of disasters. The response was influenced by both modern and inherited cultural traits, which can be identified and analysed in order to explain public reactions to the event. A new model is proposed in which culture and history combine with physical hazards to influence vulnerability.

Keywords: natural disasters; risk factors; resilience; L'Aquila earthquake (2009); sociology of risk; social vulnerability.

\section{Introduction}

For many years there has been an imbalance between the resources invested in disaster response and those dedicated to the prevention and mitigation of disasters. The world community and most individual countries have preferred to tackle the problem by responding to adverse events rather than anticipating them. There are several reasons why this position has become harder and harder to maintain. To begin with, knowledge of hazards is now substantial at the world scale and increasingly so at the local scale in many parts of the world (Mercer et al., 2010). Hence, a plea of ignorance no longer carries weight. Secondly, the number of people affected by disaster, about 280 million in 2010, is expected to rise to 375 million in 2015 (IFRCRCS, 2010). Thirdly, climate change will probably intensify meteorological disasters such as floods and storms (Birkmann and von Teichman, 2010). There are non-linear relationships between physical factors, such as average wind speed or flooding level, and damage such that the latter becomes disproportionally large in relation to increases in the former. Finally, in political and diplomatic circles, there has been a gradual realisation that the benefit-cost ratios for vulnerability reduction are so high that reducing disaster risk makes sound economic sense. The UN's International Strategy for Disaster Reduction (UNISDR) and its Hyogo Framework for Action, 2005-2015, have been critical to

\footnotetext{
* Article published in RCCS 93 (June 2011).
} 
this process (UNISDR, 2005). Hence, the problem of disasters has become difficult for governments to ignore.

As a result of these factors, the early years of the new millennium are a period of intense change in the ways in which humanity understands, interprets and lives with disaster. Since 1970 there has been an increasing divergence in the process of wealth accumulation between the minority of rich people and the majority of the poor (Massey, 1996). Although poverty and vulnerability to disasters are not perfectly synonymous, they are nearly so, and conversely, wealth can be equated with protection and safety. This simple balance, however, does not reduce the potential for massive financial losses in areas where both hazards and physical capital are heavily concentrated.

Broadly speaking, vulnerability is the potential for harm or loss inherent in a person or thing (Weichselgartner, 2001). The word has specific meanings in particular disciplines, for example social work and psychology (Furedi, 2004). In disaster studies, it is the key to understanding impacts (Birkmann, 2006). Since the late 1970s there has been a gradual realisation that natural, technological, social and intentional (i.e. terrorism) hazards are merely the trigger of a set of complex reactions governed by the social, economic, cultural and physical vulnerability of society (Hewitt, 1983). Hence, there has been an increasing realisation that it is important to know and reduce human vulnerability to disasters in its many different forms.

As a prelude to proposing new models of disasters and their abatement and management, the next section discusses the bases of theory in this field.

\section{Basic Models of Disaster Risk Reduction (DRR)}

The word 'resilience' or 'resiliency' is sometimes thought to be derived from ecological studies of the survival of species (Adger, 2000), but in reality it has its origins about a century ago in the mechanics of materials testing. A resilient material has an optimum combination of rigidity, which enables it to resist an applied force, and flexibility, which enables it to absorb that which it cannot resist. Its breaking point occurs at a very high level of applied force (Avallone et al., 2007). By analogy, society needs to develop the capacity to resist and absorb (i.e. adapt to) the forces that cause disaster. Societal resilience involves the setting aside of resources against future contingencies, and the process of preparing to withstand future shocks (Manyena, 2006). At the root of it are prudence and foresight. 
Caveat lector: there is an alternative to the conceptual equation that is so often employed to explain disaster risk (Alexander, 1991):

$$
\text { hazard } \times \text { vulnerability [ } x \text { exposure ] }=\text { risk } \rightarrow \text { disaster }
$$

The world has accumulated a vast store of both material wealth and knowledge, but it has not established priorities that enable it to reduce disaster risk sufficiently to avoid massive and widespread suffering and misery. Given the propensity to spend - some would say squander - vast sums on largely unproductive enterprises (for example, three trillion US dollars on the war in Iraq), one might be tempted to rewrite the equation as:

$$
\text { hazard } \times \text { waste }[\times \text { exposure }]=\text { risk } \rightarrow \text { disaster }
$$

Be that as it may, disaster risk reduction should involve investigating the hazards, protecting local populations, planning and preparedness to use resources wisely, hazard avoidance (where possible) and incident management. The key resources are knowledge, organisation and communication (Fothergill, 2000). None of these is necessarily expensive. The relative cost of information technology is falling, and mechanisms for sharing and diffusing knowledge are multiplying.

Knowledge can be divided into three sectors: on hazard impacts, on community vulnerability, and on the coping mechanisms that produce resilience. It is necessary to avoid the tendency to relate the knowledge merely to past disasters, rather than to future ones. Scenarios are vital to understanding those hazards that can in any way be anticipated, especially the recurrent and seasonal ones, but a scenario is not a projection of the past into the future, rather it is an investigation of possible future outcomes with the aid of information gained from past events (Schoemaker, 1993). Changing vulnerabilities, emerging risks and intensifying hazards all conspire to ensure that disasters do not repeat themselves, even though they may have a degree of predictability.

Disaster risk reduction is therefore a question of organisation and resources. The former can be divided into imposed organisation and self-organisation. Of these, the first is mandated by authority and comes from outside the community. It includes laws, protocols, directives and standards. The second involves indigenous coping mechanisms that the community develops for itself, including local planning and volunteer work (Mercer et al., 
2010). Likewise, resources can be divided into those pertaining to the community and those provided from outside the area, in some cases at the scale of international disaster relief and assistance for risk reduction. Long experience has shown that there is an uneasy dialectic between indigenous and imposed disaster risk reduction (Mercer et al., 2007). In ideal circumstances, the best of local practice is complemented and reinforced by appropriate methodology derived from outside the area (Briggs, 2007). Such a balance is not easy to achieve, and it requires a mixture of cultural sensitivity, political equilibrium and plain common sense, as well as the technical know-how and social consensus to reduce disasters.

Despite a need that stretches back through all of human history, in its modern form disaster risk reduction is a child of the 2000s (Alexander, 2008). It intertwines with the resilience and climate change adaptation agendas. It also responds to the imperative of sustainability. The world is consuming at least 50 per cent more resources than it can produce or find, and, moreover, it will have to adapt to warmer conditions and rising sea levels, as well as potentially more extreme natural phenomena that cause disasters (UNISDR, 2009). These are some of the motives for advocating a sustainable response.

Disasters can set back development. For instance, in Nicaragua it was estimated that Hurricane Mitch in 1998 did enough damage to retard development by 20 years (Wisner, 2001). Hence, disaster risk reduction is part of the sustainable development agenda. However, sustainability is a controversial issue and there is no single definition of what is sustainable. There is, however, a consensus that sustainability requires a degree of harmony between humans and nature, and some level of conservation of the natural resource base (Saunier, 1999). Disaster risk reduction can contribute to the processes involved. In addition, there are questions of sustainability with regard to DRR in its own right. Programmes have failed because of lack of consistent funding, unclear or inappropriate objectives and lack of political or social support. In synthesis, sustainable programmes of disaster risk reduction are built upon governance, defined here as a participatory form of democracy in which institutions have public support and stakeholders are empowered such as to have direct involvement in decision making. Governance is at the root of vulnerability reduction, disaster preparedness and the development of coping mechanisms (Ammann, 2006).

These observations constitute a simple framework for analysing human responses to the threat and impact of disasters. However, there is a need for new theory. Much of the existing body of theory stems from the ideas of cultural ecology, or human ecology, 
promulgated in the 1920s and developed most fully in the 1960s (White, 1974). Since then there have been momentous changes in society, economy and the environment of life. Moreover, the accelerating pace of global change shifts the parameters of theory yet more. For example, the information technology revolution has been compared to the effect of the invention of printing (Quarantelli, 1997). It has had a profound impact on many different forms of human activity and social relations. If we are to understand disasters in the $21^{\text {st }}$ century, it will be necessary to look for new sources of explanation, new models that are capable of unravelling the complexity of a rapidly changing milieu. The theory developed in the 1960 s and 1970 s is no longer able to do that.

\section{Towards a New Theoretical Basis for Disaster Studies}

The modern world is characterised by increasing imbalances in access to wealth and resources, in safety and in opportunities for betterment (Massey, 1996). Misuse of resources and excessive emphasis on economic development without taking into account the full costs may exacerbate these disequilibria. New theory needs to be able to describe and interpret this situation, as well as respond to the profound changes in global interconnectedness that are occurring.

Human ecology posits a relationship between people and their environment in which technology can overcome some of the difficulties, but nature is not easily dominated and hence there must be adaptation to extremes (White, 1974). In the original work, the model is based on the work of Herbert Simon on the rational man who makes economic decisions as an optimiser, by maximising opportunities to gather information, or a satisficer, by choosing rationally from a limited range of options (Simon, 1956). Evidently, this model allows no room for cultural or ideological variations and only the most limited opportunity for perception to govern choice. In reality, there is a constant dialectic between factors that increase risk (for example, stronger hurricanes, building new settlement in vulnerable areas, water management that increases downstream flood risk) and those that diminish it, the actions of disaster risk mitigation. The dialectic is further modified by risk perception, which can either increase or decrease vulnerability, depending on its level of salience and accuracy. Hence, in schematic terms: 
Total vulnerability to disasters $=$

Risk amplification processes -

Risk mitigation processes \pm

Risk perception factors

In disaster risk reduction, decisions, actions and results all depend on a complex interaction between perception and culture.

\section{The Importance of Culture and Symbolism in Disaster Risk Reduction}

Remarkably few academic studies of disaster tackle the problem of culture (Gheradi, 1998). The term can be defined as an assemblage of shared beliefs, opinions, social characteristics and attitudes. Culture is extremely difficult to measure in any social scientific way (Brislin, 1980). One reason is that it is an elusive and multi-faceted concept, one that changes with social context. Another is that culture is, like Chinese boxes or Russian dolls, a set of nested phenomena: we respond to different cultures related to national, regional and local settings; peer groups, families and workplaces; ethnic and social groups; gender and race; and interest groups. A third reason is that culture undergoes a constant process of metamorphosis as it adapts to the changing circumstances of the modern world and how we are able to interpret it. As a result, there are very few reliable measures of culture. It is nonetheless highly important. If one wants to promote change, success is more likely if it is compatible with the prevailing culture, while if it runs against the culture, the adaptive process is likely to be blocked for apparently illogical reasons.

Each of us inherits a cultural background that is more or less evident depending on the strength of ties to particular places and social groups. We spend our lives accumulating cultural characteristics by processes of learning and assimilation. These are the emic components of culture - those that are specific to a particular cultural context. The etic aspects are related to universal traits and are the source of much cultural metamorphosis. In the present age they are mostly the result of the diffusion of mass culture and the technology that propagates it. Hence, modernism fuses with ancient cultural traditions: symbiotically, the former is interpreted in the light of the latter (Figure 1).

Figure 1 illustrates that culture is not a static phenomenon, but one that carries its own dynamism. Nevertheless, we should not be beguiled by its dynamic aspects, namely the mass-consumer culture inherent in the etic, or universal, aspects of modern life. 


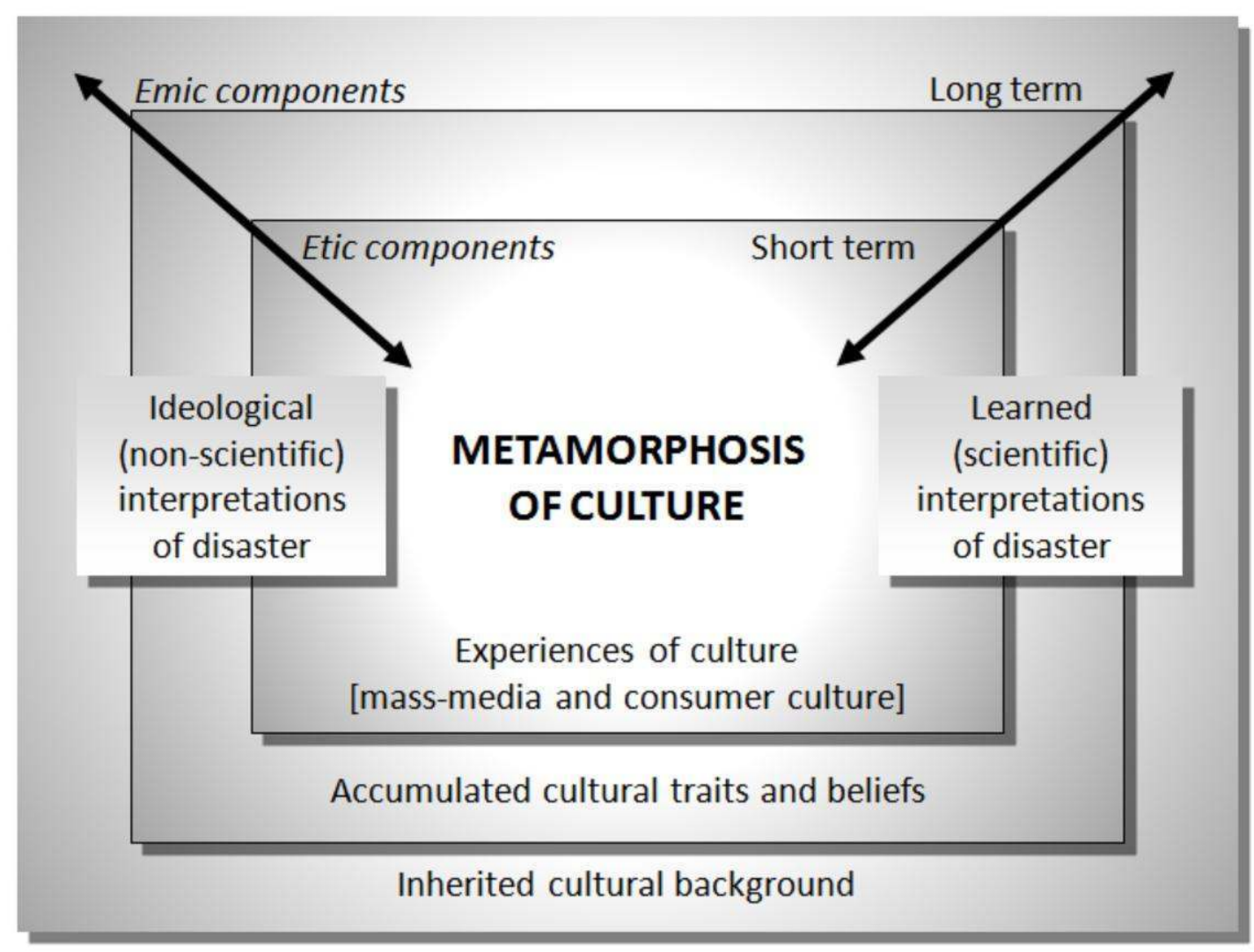

Figure 1. The architecture and metamorphosis of human culture

These are important sources of cultural uniformity in the modern world, but we should remember that beneath them there are accumulated and inherited traits that are also capable of influencing our attitudes and responses to disaster. The next section will show that the response to the 6 April 2009 earthquake in L'Aquila, central Italy, demonstrates a sudden, almost spontaneous desire for modernity, as evinced by forms of reconstruction that show a distinct break with traditional urban form. In contrast, the political power relations that conditioned the choices made in the reconstruction process reflect more the weight of history, the emic processes of a social fabric that is slow to evolve, than the etic ones found in modernism.

Culture is important to any understanding of the significance and role of disaster in the modern world because it determines how perception is interpreted, and, indeed, may even determine what is perceived. Thus we understand disaster through a perceptual and cultural filter that has many levels, from individual, through family, peer group, organisation, community, region and nation, right up to the international, etic forms of popular culture. By way of example, community-based forms of disaster reduction should take account of the 
ways in which people in the community associate with each other, including forms of meeting and debate (the socialisation of the problem) and community power structures and sources of authority. All of these elements are to some extent culturally determined.

In this context, students of disaster have largely ignored the role of symbols and symbolism. Yet they have been important throughout history and are no less relevant today, albeit in a radically different context (Alexander, 2004). Once upon a time the appearance of a comet in the sky might have been interpreted as a portent of doom and destruction. Nowadays symbols are the simplest form of model of a reality that is increasingly complex as more and more information becomes available. Symbols and symbolism are a natural response to the domination of communication by electronic representations of reality, many of which are severely reductive.

One effect of the information technology revolution has been to change the symbolic interpretation of disaster. Sixty years ago to be involved in disaster was, in many cultures, to be subject to a form of disgrace that could hardly be talked about. Nowadays such involvement has been radically transformed by mass media attention. To be a victim of disaster may even be a route to celebrity. This has to do with the interpretation of disaster symbolically - as a form of moral outrage (Horlick-Jones, 1995) in which the victim gains the weight of moral authority simply by being involved. However, for this to be true, much depends on the "story value" (i.e. singularity, novelty, human interest, etc.) that the mass media can attribute to the situation and its protagonists.

It may be true that the key to interpreting disasters is to be found in the works of Carl Gustav Jung ("man and his symbols," 1964), Roland Barthes ("semiotics and myth," 2009), Umberto Eco ("semiotics and popular culture," 1978) and Zigmunt Bauman ("liquid modernity," 2001). All three branches of semiotics could be involved in this process. First, semantics, the relationship between signs and the denotata, the things which they endow with meaning, can help us understand the gap between how people perceive hazard, risk and disaster and how these phenomena are in scientific terms. In previous works I listed up to 47 common misconceptions about disaster and analysed how some of these influence the judgement of people involved in managing emergencies. Secondly, syntactics, the relationships among signs in formal structures, can help us understand how the representation of disasters is codified by the groups and cultures involved. This is the shorthand interpretation of risk and impact for the purposes of rapid reaction, the language 
of response to hazard. Thirdly and finally, pragmatics, the relationships between signs and their effect on people who use them, can help us understand the feedback between the symbolic representations of disastrous phenomena, risks and extreme events and the meanings that both result from and generate these models.

A word of warning must be issued about the concepts of vulnerability and risk. They are akin to friction, a quality that does not exist until it is mobilised. Students of disaster will have noted that the 'hard' science interpretation of risk is fundamentally different from the social science interpretation (Slovic and Gregory, 1999). Engineering risk usually involves calculating the probability of failure of a built structure under specific conditions of loading. Social science risk brings into play factors such as perception that cannot easily be quantified, or when quantification is attempted the result is less than satisfying (Purchase and Slovic, 1999). Thus risk and its dominant component vulnerability are in essence hypothetical concepts. Paradoxically they are no less real for being hypothetical. However, once they are mobilised they are instantly transformed into impact. It is thus hardly surprising that risk and vulnerability remain elusive - though not illusive - concepts that defy holistic measurement or assessment. To understand either we must descend to the level of partial estimation, using a set of qualifying conditions, for example, risk over defined time periods and with respect to one sector, such as economic activity, or infection and disease.

Unfortunately, many of the ideas expressed above are only half formed. Their full development requires considerably greater and more penetrating observation over longer periods of time. In addition, such periods will inevitably be characterised by rapid and profound changes in society and the environment of life. Nevertheless, it is possible to make a start on interpreting current reality using new models. The next section will present a short example.

\section{Interpretations of the L'Aquila (Central Italy) Earthquake of 6 April 2009}

At 03:32 hrs local time on Monday 6 April 2009 an earthquake of magnitude $M_{w}=6.3$, duration 25 seconds and mean peak acceleration $0.3 \mathrm{~g}$ occurred with epicentre $3.4 \mathrm{~km}$ from the centre of L'Aquila, a city of 72,800 inhabitants located in the Apennine mountains of central Italy in Abruzzo Region. In total, 308 people were killed, 1500 were injured, 202 of them seriously, 67,000 people were left homeless and about 100,000 buildings were seriously damaged. The earthquake formed part of a swarm of tremors that began in 
October 2008 and did not attenuate until the following summer. L'Aquila had been struck by a devastating seismic event in 1703 with 6,000-10,000 deaths, but the last major earthquake in Abruzzo happened at Avezzano, about $100 \mathrm{~km}$ southeast of L'Aquila in 1915. It killed 32,000 people, including 94 per cent of the population of Avezzano. The death toll in 2009 could have been much higher had the earthquake not occurred during a long weekend when many people were away from the area.

The L'Aquila earthquake was a moderate physical event but, due to high levels of seismic vulnerability, it had a disproportionately large impact on the population of the area affected, with 16 municipalities severely damaged and up to 98 affected, 49 of them seriously. The disaster was thus a significant test of the Italian national civil protection system, which responded with a major and sustained mobilisation of national resources. Given the risk of structural collapse among buildings weakened by the earthquake, L'Aquila city and several local towns were put off limits to the general population, the first time in the history of modern Italy that a major city had been totally evacuated, moreover for a period exceeding one year (Stucchi et al., 2009).

At the time of the earthquake, rescue of the survivors was complicated by the partial collapse of San Salvatore, the main regional hospital and the one medical centre best adapted to emergency response for a mass casualty situation. Within 24 hours the first of two large field hospitals was set up and active in the vicinity, but several hours after the earthquake San Salvatore had to be taken out of use and evacuated for fear of structural collapse. Immediate medical response was thus largely carried out by military medivac, evacuation of seriously injured patients by air to hospitals in the surrounding region, most of them at considerable distance from L'Aquila.

Of the 67,000 homeless survivors, about 21,000 were accommodated in 171 tent camps, mostly in tents for eight people. A similar number were put up in hotels, many on the Adriatic coast on the other side of the Apennine Mountains. The remainder were either found accommodation on their own or left the region. The tent camps remained for six months, throughout the summer, until they were replaced with transitional housing. This was of two types: C.A.S.E. (Complessi Antisismici Sostenibili ed Ecocompatibili) and M.A.P. (Moduli Abitativi Provvisori). The CASE project consisted of 184 multiple occupancy units with antiseismic base isolation constructed at 19 sites in the vicinity of L'Aquila (Figure 2). The MAP units were smaller prefabricated buildings without base isolation that were 
erected at more than 50 sites in the area. Some 15,500 people were accommodated in the CASE units and 8,500 at the MAP sites (Calvi and Spaziante, 2009).

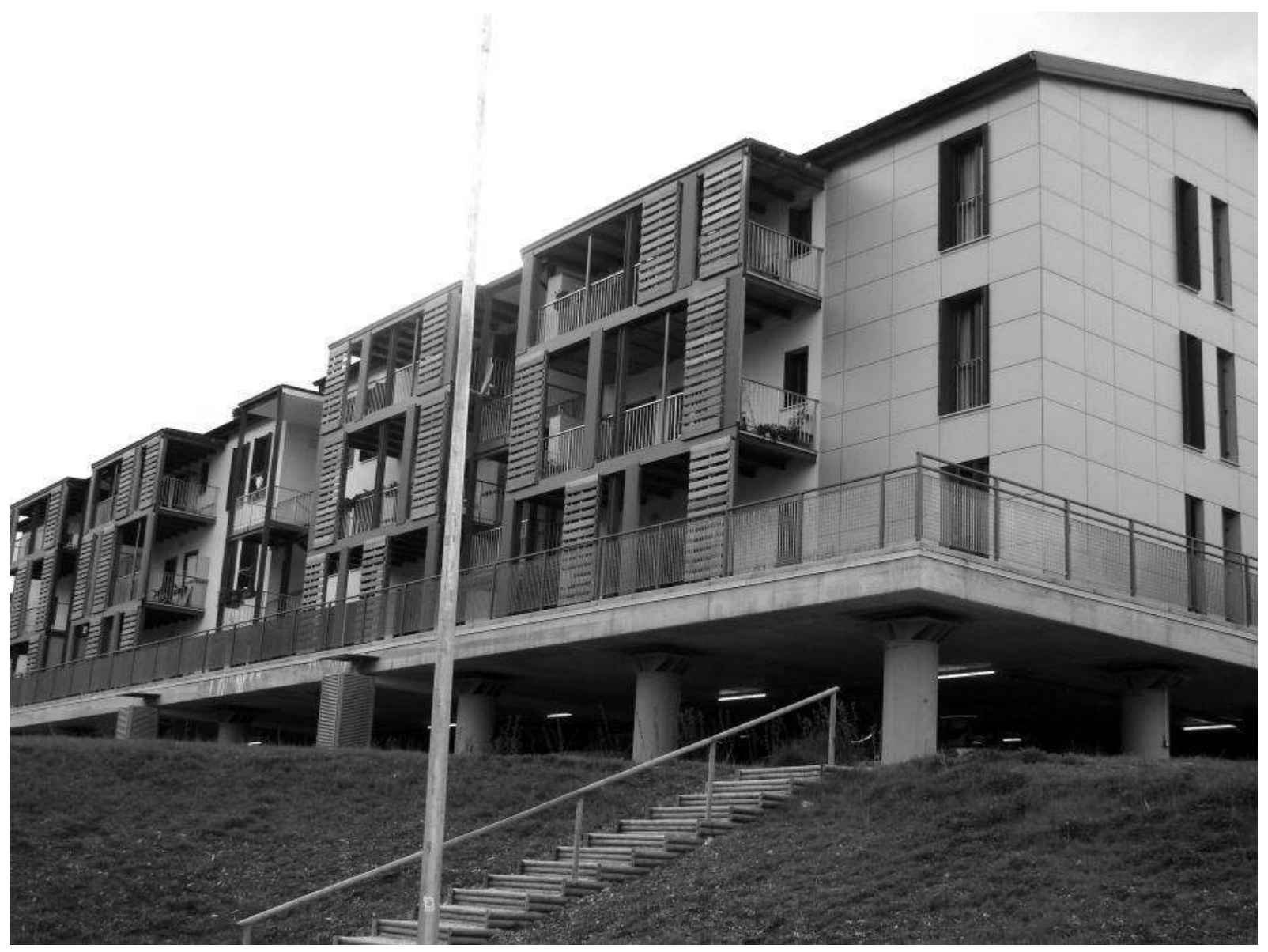

Figure 2. CASE transitional housing at Bazzano outside L'Aquila city (photo by author). The base isolation columns support the building and protect it from earthquake shaking.

The Italian Government's immediate- and short-term strategies for managing the earthquake involved the doctrine of overwhelming force (Alexander, 2010). Huge numbers of vehicles and vast stockpiles of materials were rapidly assembled and applied to the problems of cordoning off the areas of destruction, buttressing precarious buildings, feeding and housing displaced populations and coordinating the flow of relief goods and personnel. As usual, the Italian Fire Brigades constituted the lead agency. Blue-light services and the hundreds of civil protection volunteer organisations were coordinated by the National Department of Civil Protection. The strategy was successful, but it remains to be seen whether such a measure could be adopted in the case of a major earthquake over a much wider area and involving a much larger population.

The medium-term strategy is yet more controversial. Because of the damage to 
vernacular housing, earthquake disasters involve sudden and massive homelessness. The most common strategy for dealing with this is to use tents and improvised shelter for a very short period of time (a matter of days or a very few weeks) and then provide cheap but robust transitional shelter using container homes or small, light-walled prefabs, which typically have a floor area of 30-40 sq. metres and are allotted as one per family (Aysan and Davis, 1992).

The cost of such housing is usually in the range $12,000-15,000$ per unit, including the minimum essential urbanisation of sites and construction of temporary networks for the distribution of utilities. In L'Aquila the cost of the CASE units worked out at $€ 3,750$ per square metre, an average of $€ 280,607$ per family unit (Calvi and Spaziante, 2009), as much as a comparable apartment in a major city. At the same time much money was spent on intensively buttressing the ruined buildings in the town centres, which remained cordoned off against public access. However, the government could not afford to remove the estimated 4-5 million tonnes of rubble from these sites. The CASE units did not live up to their designation as 'ecocompatible'. Although they have solar panels for water heating, lack of services and public transportation has induced a massive dependency on the private car.

In the meantime nothing has been done to improve the local infrastructure or access to services. Nor has the economy been bolstered. There is evidence of economic stagnation, outmigration of workers and the loss of something between 16,000 and 26,000 jobs as a direct result of the destruction of shops, studios and businesses by the earthquake. Moreover, the devolution of taxation so ardently promoted by successive Italian governments since the 1990s has proved advantageous to some provinces of Italy and fiscally regressive to others. L'Aquila is the worst affected example of the latter.

The Italian Government's overall strategy for coping with the L'Aquila earthquake is difficult to analyse in anything but political terms. In mid-2009, the Prime Minister, Silvio Berlusconi, afflicted by scandals and loss of popularity, pledged to rehouse within six months all the families made homeless by the earthquake. Hence they were left in tents during the long hot summer and as the autumn weather cooled they were rehoused in the rapidly constructed CASE and MAP units. It was a remarkable logistical achievement, and one that involved little or no loss of quality between the design and the realisation of all the homes. It gave the Government and Prime Minister a substantial political advantage that they were able to exploit, adroitly, in order to gain votes in regional and local elections. 
However, the rehousing was achieved at a very high price. To begin with, the cost of the transitional housing was more than twenty times what more economic shelter would have cost. Secondly, nothing was invested in transportation and services, leaving sites that had populations of up to 2,500 people devoid of shops, community centres, coffee bars, bus services, clinics, schools and doctors' surgeries. Moreover, little attention was paid to the problem of conserving social cohesion in the assignment of transitional housing units. This has led to high levels of isolation, depression and post-traumatic stress among the assignees. In conclusion, the lavish scale of buttressing and vast sums spent on transitional housing have left little or nothing for reconstruction. The physical aspect of these two initiatives suggests that the Government has prepared the way for a long interval, perhaps decades, before reconstruction occurs - if it ever does. There is a precedent for this as the Belice Valley of western Sicily, another Italian backwater, went through 15 years of stagnation between the earthquakes of 1968 and the inauguration of a significant amount of reconstructed housing and urban services (Angotti, 1977).

The political symbolism of giving homeless people decent housing cannot be underestimated. The Italian Government provided everything, right down to furniture, cutlery, crockery, linen, televisions and electrical equipment. The model for this is Milano Due, the speculative residential development in Segrate, Milan, built over the period 197079, that propelled Silvio Berlusconi from obscurity to national prominence. Largesse was an instantaneous vote winner, but state paternalism has destroyed governance, in the sense intended by the definition given earlier in this paper. Dissent is barely tolerated and L'Aquila has once again become politically, economically and socially marginalised in national life. The tyranny of geography is that, although it is barely $120 \mathrm{~km}$ from the centre of Rome, L'Aquila lies in an intermontane basin with relatively poor connections to other parts of Italy. Its only major source of employment is the local university, at a time in which Italian higher education is in a state of very severe depression.

In L'Aquila political protest and dissent have been dealt with by government forces using violence and intimidation. Taxation has been inimical to enterprise. Emergent groups have been created, but they have not achieved the critical mass or prominence to have much influence on a situation characterised by stagnation and decline. The ancient cultural background of the area is characterised by poverty and feudal dependence. Although absolute poverty has gone, traces of the feudal dependence remain, along with the 
economic depression of a region that has not been given the best possible incentives to grow and develop its rather scarce resources. Although chronicles of the miseria of the peasant area are in no way diagnostic of modern conditions, there are parallels in the inherited cultural background, especially in the conservatism of a people that for too long has had too much to lose by protesting (Russo, 1955). The biggest victim is good governance and any prosperity that might have resulted from it.

One characteristic of traditional societies seems to be the particular plight of women. Although the situation in L'Aquila is not as severe as it is in many countries, the earthquake nevertheless created a discernable gender bias (cf. Enarson and Morrow, 1998). More women were killed than men, especially in the age groups 30-39 and 70+. Even when one corrects for the demographic imbalance between the sexes in old age, the anomaly remains (Alexander, 2011). The explanation is difficult to formulate but probably relates to the lower mobility of women than men: some of the men who were registered as resident in the area were probably not physically present on the night of the earthquake. Whatever the explanation, research has revealed that women also suffered more than men from posttraumatic stress during the months after the earthquake (Dell'Osso et al., 2011).

The L'Aquila earthquake and its aftermath are open to various forms of symbolic interpretation. To begin with, it was the first major test of the current Italian civil protection system since the 1980 earthquake in southern Italy. It thus reflected the competence of the nation in the face of a severe natural emergency. Secondly, the whole disaster was overshadowed by political considerations, in the light of the Italian government's need to gain short-term popularity for electoral reasons and in order to maintain its power base. The G8 summit that was held in L'Aquila from 8-10 July 2009 represented the apex of this process. In reality the summit did little for the plight of the Aquilani, but it was redolent with symbolic moments. For example, the village most affected by the earthquake was Onna, in which 40 of the 300 inhabitants died when 60 per cent of the building stock collapsed. On 11 June 1944 Onna had been the scene of a massacre of 18 local civilians by German troops and during the summit the German Foreign Minister pledged funds towards the post-earthquake reconstruction, a highly symbolic gesture in the light of current moves towards European unity.

Like many modern catastrophes, the L'Aquila earthquake was a drama played out in the mass media, especially television, which maintained a constant presence there for weeks. 
Modern post-disaster solidarity has a very public face, much at variance with the discretion of previous ages (Alexander, 2006). However, the problem with media coverage is that it does not necessarily present a consistent and accurate picture of the reality on the ground. Coverage varies from day to day much more than the situation itself does. Moreover, many of the most serious problems, for example bureaucratic stagnation, are not particularly newsworthy. In contrast, it proved easy to interpret the disaster in terms of, for example, the charity, piety and pity inherent in Catholicism, one of the principal cultural subtexts.

Finally, despite economic stagnation, lack of reconstruction and lack of improvement of the local infrastructure, some remarkable transformations occurred in the L'Aquila area. For instance, construction in the region has for centuries been dominated by the use of stone from which reinforced concrete has taken over (with decidedly mixed results in terms of seismic response). Suddenly, in the aftermath of the earthquake there was an enormous accession of wood and steel construction, much of it arranged in parks, or estates, in the Anglo-Saxon manner. Symbolically, it seemed to represent a sudden modernisation of a very ancient area (L'Aquila city is 1000 years old and many of the surrounding settlements are twice as ancient), or at least a desire for modernisation. Given the paternalism and lack of governance, one might almost call it a forced modernisation. There is a strong risk in such cases that it will destroy a genius loci acquired over the centuries. In Italy historic settlements depend for their identity on a number of iconic monuments and a distinctive kind of urban form. To erase any of that would only cut people off from their history and diminish their sense of social identity. There would thus be discord in the semantics of semiotic analysis, and probably also in the pragmatics (Eco, 1978).

Much more could be done to interpret the situation in L'Aquila in semiotic terms, and the raw material is definitely available. However, that must await further research and in the meantime it is necessary to draw some conclusions.

\section{Conclusion: Social Models of Disaster}

The earliest human ecological models of disaster were linear in conception. Hazard acted upon vulnerability to produce disaster. It followed that, as hazards were at the start of the process, they received the lion's share of the attention. This was also in line with the dominance of physical over social sciences at the time. Over the period 1979-83, researchers working in developing countries produced the so-called "radical critique," which argued that 
in the explanation of disaster vulnerability carries more weight than hazard (Hewitt, 1983). As a result of feedback loops, hazard can be regarded as a trigger for the social processes that create vulnerability, which is the principal determinant of disaster potential.

Increasing knowledge of disasters and the social processes involved, and the complexity of life in the early $21^{\text {st }}$ century, suggest that a new model ought to be formulated (Figure 3 ). The vulnerability of human socio-economic systems is acted upon by physical hazards (whether natural or anthropogenic), as well as cultural and historical factors. The plexus of the context and consequences of these associations is what determines the form, entity and size of any ensuing disaster.

“LINEAR" MODEL:

HUMAICAL
EVENT $\longrightarrow \begin{gathered}\text { HUMAN } \\ \text { VULNERABILITY } \\ \text { CONSEQUENCES } \\ \text { OF DISASTER }\end{gathered}$

"RADICAL CRITIQUE" (K. HEWITT et al.):

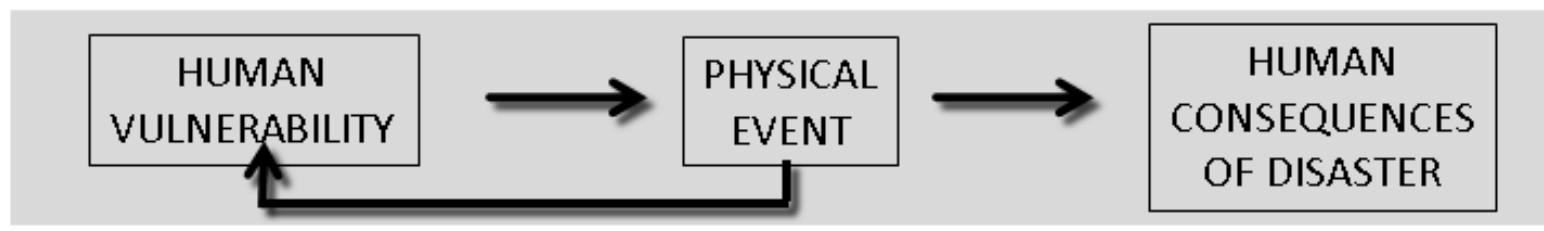

PROPOSAL FOR A NEW MODEL:

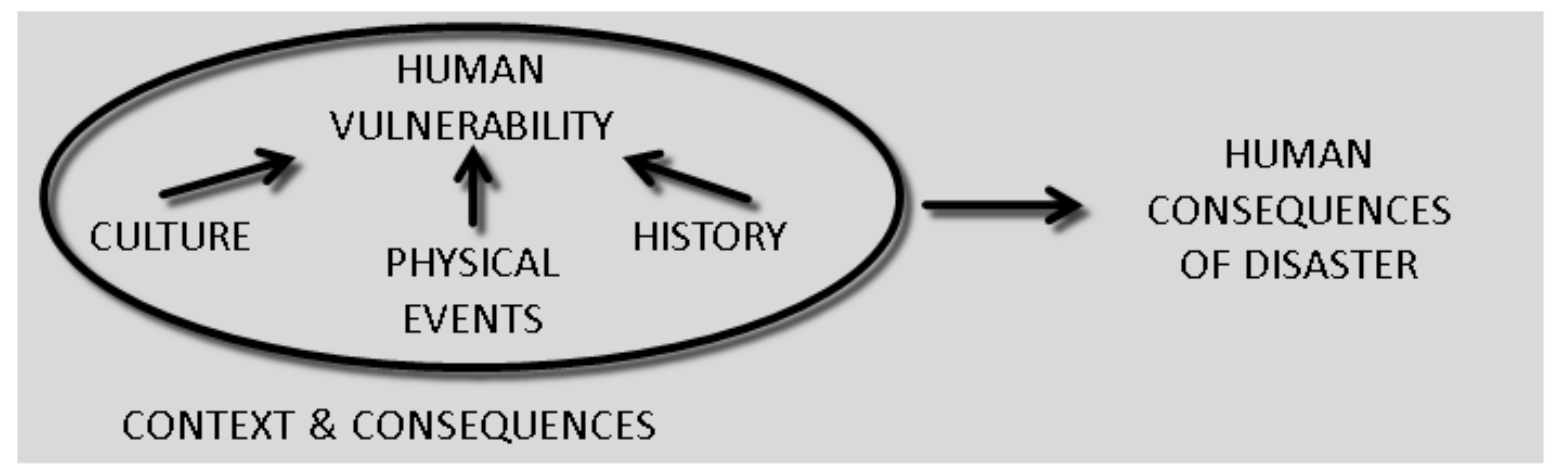

Figure 3. Possible evolution of models of disaster

Clearly, this model is both preliminary and schematic. Much work needs to be done to fill in the details and clarify the relationships. For instance, history is a vital explanatory factor (and we live in an age that is apt to forget its lessons), but it does not determine the future, it merely contributes some important ingredients. Much lateral thinking will be required if disaster is to be interpreted creatively and with penetrating insight. Trends and tendencies 
will have to be understood and incorporated into this process, and we live in a world that is consuming resources at an accelerating rate, that is undergoing environmental change at an ever faster speed, and that is becoming increasingly crowded with people who live, travel and work in hazardous areas. Finally, any valid, workable explanation of disaster for the new millennium must include the effects of technological change, which has radically altered the ways in which we see and interpret catastrophe. Hence, we face both an intellectual and a practical challenge, which is worth rising to, as theory is the "road map" by which we navigate through the chaos of disaster and risk situations and are thus able to manage them.

\section{References}

Adger, W. Neil (2000), "Social and Ecological Resilience; Are They Related?" Progress in Human Geography, 24(3): 347-364.

Alexander, David E. (1991), "Natural Disasters: A Framework for Research and Teaching," Disasters, 15(3): 209-226.

Alexander, David E. (2004), "An Interpretation of Disaster in Terms of Changes in Culture, Society and International Relations," in R.W. Perry and E.L. Quarantelli (eds.), What is a Disaster? New Answers to Old Questions. Philadelphia: Xlibris Press, 1-15.

Alexander, David E. (2006), "Globalization of Disaster: Trends, Problems and Dilemmas," Journal of International Affairs, 59(2): 1-22.

Alexander, David E. (2008), "Mainstreaming Disaster Risk Management," in Lee Bosher (ed.), Hazards and the Built Environment: Attaining Built-in Resilience. London: Taylor and Francis, 20-36.

Alexander, David E. (2010), "The L'Aquila Earthquake of 6 April 2009 and Italian Government Policy on Disaster Response," Journal of Natural Resources Policy Research, 2(4): 325-342.

Alexander, David E. (2011), "Mortality and Morbidity Risk in the L'Aquila, Italy, Earthquake of 6 April 2009 and Lessons To Be Learned," in Robin Spence, Emily Ho and Charles Scawthorn (eds.), Human Casualties in Earthquakes. Progress in Modelling and Mitigation. Advances in Natural and Technological Hazards Research, vol. 29. Berlin: Springer, 185-198.

Ammann, Walter J. (2006), "Risk Concept, Integral Risk Management and Risk Governance," in Walter J. Ammann, Stephanie Dannenmann and Laurent Vulliet (eds.), Risk 21: Coping with Risks Due to Natural Hazards in the 21st Century. London: Taylor and Francis, 3-23.

Angotti, Thomas (1977), "Playing Politics with Disaster: The Earthquakes of Friuli and Belice (Italy)," International Journal of Urban and Regional Research, 1, 327-331.

Avallone, Eugene A.; Baumeister III, Theodore; Sadegh, Ali (2007), Marks' Standard Handbook for Mechanical Engineers. New York: McGraw-Hill Professional [11 ${ }^{\text {th }}$ ed.].

Aysan, Yasemin; Davis, lan (eds.) (1992), Disasters and the Small Dwelling: Perspectives for the UN IDNDR. London: James and James.

Barthes, Roland (2009), Mythologies. London: Vintage.

Bauman, Zygmunt (2001), Community: Seeking Safety in an Insecure World. Cambridge: Polity Press.

Birkmann, Jörn (ed.) (2006), Measuring Vulnerability to Natural Hazards: Towards Disaster Resilient Societies. Tokyo: United Nations University Press. 
Birkmann, Jörn; von Teichman, Korinna (2010), "Integrating Disaster Risk Reduction and Climate Change Adaptation: Key Challenges - Scales, Knowledge, and Norms", Sustainability Science, 5, 171-184.

Brislin, Ronald W. (1980), "Cross-Cultural Research Methods: Strategies, Problems, Applications", in Irwin Altman, Amos Rapoport and Joachim F Wohlwill (eds.), Human Behavior and Environment, Vol. 4-Environment and Culture. New York: Plenum Press, 47-82.

Calvi, G.M.; Spaziante, V. (2009), "Reconstruction between Temporary and Definitive: The CASE project", Progettazione Sismica, 03, 221-250.

Dell'Osso, L.; Carmassi, C.;Massimetti, G.; Daneluzzo, E.; Di Tommaso, S.; Rossi, A. (2011), "Full and Partial PTSD among Young Adult Survivors 10 Months after the L'Aquila 2009 Earthquake: Gender Differences", Journal of Affective Disorders, 131(1-3), 79-83.

Eco, Umberto (1978), A Theory of Semiotics. Bloomington, IN: Indiana University Press.

Enarson, Elaine; Morrow, Betty Hearn (eds.) (1998), The Gendered Terrain of Disaster: Through Women's Eyes. Westport, CT: Greenwood.

Fothergill, Alice (2000), "Knowledge Transfer between Researchers and Practitioners", Natural Hazards Review, 1(2), 91-98.

Furedi, Frank (2004), Therapy Culture: Cultivating Vulnerability in an Uncertain Age. London: Routledge.

Gheradi, Silvia (1998), "A Cultural Approach to Disasters", Journal of Contingencies and Crisis Management, 6(2), 80-83.

Hewitt, Kenneth (1983), "The Idea of Calamity in a Technocratic Age", in Kenneth Hewitt (ed.), Interpretations of Calamity. London: Unwin-Hyma, 3-32.

Horlick-Jones, Tom (1995), "Modern Disasters as Outrage and Betrayal", International Journal of Mass Emergencies and Disasters, 13(3), 305-315.

IFRCRCS (International Federation of Red Cross and Red Crescent Societies) (2010), World Disasters Report 2010. Focus on Urban Risk. Geneva: IFRCRCS.

Jung, Carl Gustav (ed.) (1964), Man and His Symbols. New York: Aldus Books.

Manyena, Siambabala Bernard (2006), "The Concept of Resilience Revisited", Disasters, 30(4), 434450.

Massey, Douglas S. (1996), "The Age of Extremes: Concentrated Affluence and Poverty in the Twentyfirst Century", Demography, 33(4), 395-412.

Mercer, Jessica; Dominey-Howes, Dale; Kelman, Ilan; Lloyd, Kate (2007), "The Potential for Combining Indigenous and Western Knowledge in Reducing Vulnerability to Environmental Hazards in Small Island Developing States", Environmental Hazards, 7(4), 245-256.

Mercer, Jessica; Kelman, Ilan; Taranis, Lorin; Suchet-Pearson, Sandie (2010), "Framework for Integrating Indigenous and Scientific Knowledge for Disaster Risk Reduction", Disasters, 34(1), 214-239.

Purchase, lain F.H.; Slovic, Paul (1999), "Quantitative Risk Assessment Breeds Fear", Human and Ecological Risk Assessment, 5, 445-453.

Quarantelli, Enrico Louis (1997), "Problematical Aspects of the Information/ Communication Revolution for Disaster Planning and Research: Ten Non-technical Issues and Questions", Disaster Prevention and Management, 6(2), 94-106.

Russo, Giovanni (1955), Baroni e contadini. Bari: Universale Laterza. 
Saunier, Richard E. (1999), "Sustainable Development, Global Sustainability", in David E. Alexander and Rothes Whitmore Fairbridge (eds.), Encyclopedia of Environmental Science. Dordrecht: Kluwer, 587-592.

Schoemaker, Paul J. H. (1993), "Multiple Scenario Development: Its Conceptual and Behavioral Foundation", Strategic Management Journal, 14(3), 193-213.

Simon, Herbert A. (1956), "Rational Choice and the Structure of the Environment", Psychological Review, 63, 129-138.

Slovic, Paul; Gregory, Robin (1999), "Risk Analysis, Decision Analysis and the Social Context for Risk Decision Making", in James Shanteau, Barbara A. Mellers and David A. Schum (eds.), Decision Science and Technology: Reflections on the Contributions of Ward Edwards. Norwell, MA: Kluwer, 353-365.

Stucchi, Massimiliano; Meletti, Carlo; Manfredi, Gaetano; Dolce, Mauro (eds.) (2009), "L'Aquila, April 6th 2009, 3:32am", Progettazione Sismica, 03, 1-256.

UNISDR (United Nations International Strategy for Disaster Reduction) (2005), Hyogo Framework for Action 2005-2015: Building the Resilience of Nations and Communities. Genebra: UNISDR.

UNISDR (United Nations International Strategy for Disaster Reduction) (2009), "Strengthening Climate Change Adaptation through Effective Disaster Risk Reduction." ISDR Briefing Note 03. Genebra: UNISDR. Available at http://www.unisdr.org/preventionweb/files/16861 ccbriefingnote3.pdf.

Weichselgartner, Juergen (2001), "Disaster Mitigation: The Concept of Vulnerability Revisited", Disaster Prevention and Management, 10(2), 85-94.

White, Gilbert F. (1974), "Natural Hazards Research: Concepts, Methods, and Policy Implications", in Gilbert F. White (ed.), Natural Hazards: Local, National and Global. New York: Oxford University Press, 3-16.

Wisner, Ben (2001), "Risk and the Neoliberal State: Why post-Mitch Lessons Didn't Reduce El Salvador's Earthquake Losses", Disasters, 25(3), 251-268. 